\title{
Reviews
}

edited by Philip Barker

Anne Brockbank, Ian McGill and Nic Beech, Reflective Learning in Practice, Aldershot: Gower Publishing, ISBN: 056608377 9. £49.50.

The literature on independent learning suggests three sets of capacities are needed by the learner: strong motivation, self-management and reflection. Of the three, most educators readily understand the need for motivation (though how to help learners with this remains problematic) and many resources, approaches and techniques exist to help learners develop self-management. The third requirement, capacity to reflect, is much less understood. So a book with the title 'reflective learning in practice' seems welcome.

The book is organized in three parts: 'Purpose and themes', 'On the journey - learning through and around development programmes', and 'On the journey - enabling effective learning'. Readers might not see immediately the shape of the book from this, indicating a difficulty - there is not an altogether clear distinction between its parts. Part 1 is the most theoretical (and - be warned - it is not an easy read); Parts 2 and 3 are collections of case studies of learning within organizations. Part 2 differs from Part 3 in that 'the learning processes' have 'some programmed element at their centre' (p. 3). The authors rightly make the point that learning is not limited to attending training courses; organizations need to be open to the full range of potential learning experiences.

The book is about reflective learning within organizations. These are diverse, for example the following are featured: Sterling Bank, Sainsbury's, the NHS, Novartis, Pearl Assurance, Thus plc, Kodak, Allied Distillers and Norwich Union. Yet the authors take a discouraging view of the potential for such learning in a corporate context, in which 'legal rights of proprietors take precedence over those of the employee' (p. 7). Dominated by the 'rationalist tradition' in British management, the 'emotional content of learning' is resisted, yet this is 'essential for energising the learner, as well as being a critical component of deeply reflective learning' (p. 20).

Thus a gloomy backdrop is set for the case studies. These are a mixed bag - some much more optimistic in tone than one might imagine from the first part of the book. In fact, some case studies come uncomfortably close to selfpublicity and corporate public relations.

The tone of some of these strikes an uncomfortable contrast to the somewhat oppressively academic discourse of the earlier chapters. As does the cosy in-talk of the consultant in Chapter 9.

Books comprising chapters from different hands (and many of the chapters are themselves coauthored) are invariably diverse in style and content. Even admitting the difficulty of achieving consistency across so many authors, one nevertheless yearned for a stronger editorial hand. Direct contributions from the organizations themselves would also have been interesting; the overwhelming voice is that of the management consultant/educator. What would 
Sainsbury's have said, for example, about their relationship with Manchester Metropolitan University (Chapter 7)?

The intention of the book is 'to seek integration between useful theory and theoretically insightful practice' (p. 3). This balance proves, for the most part, elusive. There is a big gap between the theory of the framework set out in Part 1 and the detail of the case studies.

The authors define reflective learning as 'an intentional process, where social context and experience are acknowledged, in which learners are active individuals, wholly present, engaging with others, and open to challenge, and the outcome involves transformation as well as improvement for both individuals and their organisation' (p. 6). This is an ambitious definition. The book advances limits to what the learner can achieve on their own: "being able to undertake reflection alone is necessary but not sufficient' (p. 7). Other people have to be present to achieve 'transformation'. I have to question this, not only through my experiences as a tutor and learner working independently in open and distance learning but also when considering saints and other outstanding individuals, who withdraw from society either actually or in spirit, precisely to achieve transformation - their own and that of others around them.

All in all, this book represents a challenge to the reader. It is unnecessarily complex, both in its treatment of the topic and in the wearisome academic style to which it often resorts. The case studies, whilst infuriating at times, do contain insights though even these can be overpowered by complex frameworks or uneven style.

\section{Roger Lewis}

HEFCE, UK

Roger Lewis and Quentin Whitlock, How to Plan and Manage an E-learning Programme, Aldershot: Gower. ISBN 056608424 4. $\mathbf{1 4 9 . 5 0 .}$

Lewis and Whitlock's How to Plan and Manage an E-learning Programme is targeted at 'organisations wanting to make productive use of e-learning'; and recognizes that 'the implications of adopting new learning strategies or delivery methods are far-reaching and usually require major development input.' Written from the perspective of planning for and managing the 'far-reaching' implications of adopting elearning, the book provides a valuable guide to this whole range of issues. It should also be noted that while the book is largely written from a commercial training perspective, the lessons are equally valid for staff managing these processes in further or higher education.

However, it is a little surprising how relatively infrequently e-learning is actually mentioned, although, as the authors point out in the introduction, this is exactly as it should be. There is little about e-learning from this perspective that is actually new. Most of the issues that arise with e-learning are the same as for other forms of open learning or for that matter from conventional classroom-based learning. What is perhaps new is that the potential of e-learning is leading many more organizations to engage with these issues and for organizations new to these issues this a clear and succinct guide.

The book is divided into twelve chapters. The first two set out the authors' general approach which may be characterized as follows: begin with the learners' needs and then follow sound curriculum development procedures. This leads them to divide the planning and management process into six stages: analysis of the learners, programme content, design, develop, pilot and run

Chapters 1 and 2 provide a general overview of this iterative process and the following chapters treat the issues arising from each of these stages in more detail.

Perhaps surprisingly the analysis of the learners begins in Chapter 3 with the consideration of the business case and marketing strategy. To readers based in the education sector this may seem an unusual place to begin, but understanding a learner's needs begins with consideration of whether the learner needs the learning that you propose to offer. This in turn leads to the question of whether you can develop, deliver and support this learning in a cost-effective manner. Chapter 3 explores these issues and provides useful guidance on how to cost and plan from this perspective.

Chapter 4 develops the analysis of learning needs from a more obviously pedagogical perspective while Chapters 5, 6 and 7 look in detail at how the response to these needs can be articulated into a set of measurable and assessable learning outcomes that can underpin the planning and development of e-learning resources. 
Chapter 8 then addresses the issues involved in supporting e-learners at all stages of their progress from initial contact to completion. The chapter includes a brief but particularly useful consideration of the role of the tutor in the support process.

Chapters 9 and 10 then address the issues involved in selecting and/or developing resources. Chapter 9 provides useful guidance about how to evaluate existing materials for use or adaptation within your programmes, while Chapter 10 examines issues surrounding determining what sorts of materials may need to be developed. Both chapters contain useful checklists of considerations and Chapter 10 also has a number of useful case studies. Indeed, overall the book makes good use of both checklists and case studies.

Chapter 11 considers the implications of developing in-house or outsourcing. Among other things this includes a useful summary of the skill sets and personnel that are likely to be required to maintain an in-house development strategy. Readets of $A L T-J$ may wish to call the resource implications of this perfectly reasonable analysis to the attention of their managers.

The final chapter looks forward to the issues involved in embedding e-learning within wider virtual or managed learning environments. Arguably, this is the weakest chapter in the book, but that is because this area is changing and developing so rapidly.

Overall the book has much to recommend it. It is clear and concise, but nonetheless covers the whole range of issues that need to be considered when adopting e-learning as an organizational strategy. It will be most useful to those managers in both education and training organizations, who, as yet, have little experience of e-learning. This book can provide a quick and effective way of getting to grips with the scope of the issues that are involved. Nonetheless, all but the most experienced managers of e-learning will benefit from Lewis and Whitlock's expertise.

Indeed, there is really only one drawback to this book and that is the price. According to Amazon the list price is $£ 49.50$. At that price no selfrespecting reviewer could really recommend its purchase, even by libraries. One cannot help but feel that the publishers are actively discouraging readers from accessing the book; and that is a shame, because it is a good book.

\section{Bruce Ingraham}

University of Teesside, UK
D. Murphy, R. Walker and G. Webb, Online Learning and Teaching with Technology: Case Studies, Experience and Practice, London: Kogan Page. ISBN: 0749435208 2001. £19.99.

The use of online learning is becoming pervasive in education whether through student- or teacher-led demand, or via management insistence or peer pressure. This book does not attempt to provide instructions on how to put a course online, instead it chronicles the experiences of early adopters of online technologies in order to help others to avoid - or at least understand - how to deal with the problems and pitfalls these early adopters have faced and grappled with.

The contributors from higher and further education institutions in Australia, Canada, Hong Kong, North America, the Pacific, and the United Kingdom relate their experiences in a number of situations. They identify the key issues, the problems they encountered, their attempts at resolution and reflect on their experience. The emphasis is not so much on the technology (the editors take a broad view of what educational technology is anyway) but rather on a critical incident that happened to the authors and how they learned and developed as an online teacher as a result of it.

The book is divided into four sections dealing with issues of student interaction; teaching and assessment; planning and development; and policy. Each case study comprises a summary of the issues raised and some background to the case, followed by the details of the case presented in two or more parts. Each part is separated by a reflective break with questions posed for the reader to consider.

The studies focusing on interaction examine cases where environments designed to be highly interactive have failed or where the interaction has lead to tension, argument or discord. In 'Flame War', Robertson reports his experience of conflict when messages to a mailing list were interpreted as a personal attack and the discussion degenerated into a 'flame war'. The reporter discusses the differences in managing debate in a classroom situation and in an online environment, and provides an insight into the additional factors that need to be considered in online discussion.

Those cases dealing with teaching and assessment consider the issues that arise in online learning both by early adopters and by 
those who felt compelled to move toward online learning and found it more rewarding than they expected it to be. In 'It seemed like a good idea at the time', Oliver discusses the unexpected outcomes arising from making what appeared to be a small and positive change to a course. The change was designed to benefit both students and teacher, and motivation was encouraged by the allocation of marks to that activity. Oliver highlights the need to monitor closely the online course and the difference in interaction, feedback and communication between the faceto-face and online modes.

The challenges to those involved in planning and development are presented in cases which describe the problems posed to those involved in planning and development issues in an atmosphere of rapid change in the type and availability of technologies; the consequent dangers of committing to particular hardware or software and the need for staff development not just for faculty but for all staff. Somekh in 'The great software gamble' reports on the experience of a large project designed to develop disciplinespecific computer-based courseware spread across a number of institutions. She describes the impact of inadequate technology and rapidly changing needs in higher education. Somekh concludes that effective use of new technologies requires a cross-discipline, integrated approach with an institution-wide development plan; and that courses need to be redesigned to incorporate varied learning and teaching approaches.

The case studies relating to policy discuss the problems and failures when staff have been obliged to develop online learning materials as a result of policy decisions, the way these shortcomings have been handled and the impact on those teaching online. In 'Who is leading whom?' Selinger tells a positive story of how teacher trainers at Warwick University addressed the disparity between the requirements of the Department for Education and Employment (DoEE) for beginning teachers to know how, when and when not to use ICT, and the gap in practice, provision, infrastructure and skills both in schools and among students. By adopting a student-led approach with just-in-time support and continuing access to support and facilities through the use of FirstClass, a programme has been developed that meets the needs of students with differing levels of skills and experience working in schools with differing degrees of infrastructure and integration of ICT. At the same time they are meeting the statutory requirements of the DoEE. By making students the agents of change they have been able to strengthen the partnership between the Institute of Education at Warwick and the schools, and move towards a role of support and development.

The reader is encouraged to 'play the game' as they read each case study by reading only Part One before pausing to reflect, note their impressions, predict what will happen next and consider what course of action they would take. At the end of the case study the reader is asked to reflect on how the situation was handled, the general issues raised and what the case and the issues mean to the reader. Through being actively involved in the development of the case, the decisions made and the outcomes one is able to draw on and benefit from the experiences of these early adopters. This method of reading can be adopted informally as an individual, in discussion with colleagues, or formally as an activity for a group of students studying the practice of online learning and teaching. Furthermore; the way in which these case studies are presented promotes and provides a means to practice that essential element in teaching reflection.

The contributors to this book are to be congratulated in their willingness to share their experiences, difficulties, solutions and the consequences of the way they addressed the problems so that the rest of us can benefit from their experience and at least try to avoid the same pitfalls ourselves.

\section{Elaine Pearson \\ University of Teesside, $U K$}

Phil Race (ed.), 2000 Tips for Trainers and Staff Developers, London: Kogan Page, 2001. ISBN 0749436883, 287 pages, $£ 22.50$.

2000 Tips for Training and Staff Developers is bursting with informative bullet points of useful tips. They appear shouting at you on every page and it is not always easy to see which tip is really important and which is a 'by the way', although the intention is not that you should read from cover to cover but dip into the book as and when the need arises.

This is where the book excels in its'wide scope. It has been largely compiled from 500 tips on teaching, lectures, group learning, using computers and open and flexible learning. 
Contents and index pages are clearly set out over three pages each and can probably take you to whatever aspect of teaching and training you are interested in.

Race is famous for his use of Post-Its in training sessions and sure enough they appear in their own short chapter with the use of flip charts. If you have not done too many training sessions you could do well to look at sections on working with difficult participants and also the section on coping with the unexpected.

The group-based training section has more subheaded bullets in light grey which are easy on the eye and seem to clarify the important points well. Getting a group of people to relax and work with one another can sometimes be helped with ice-breakers.

Rather than take the approach of giving as many roles as possible for those in the group working with the facilitator, he polarizes the issue by using the terms 'leader' and 'followship'. With a very clear focus on the learning objectives of the training sessions and alignment with assessment, I ask, 'Is the power play of the management boardroom - of leader and follower a necessary component?' Also instead of concentrating on small-group teaching methodologies such as those found in the Jaques (2000) book which encourage positive interdependence - getting learners to rely on each other to learn - there are two long chapters on how adverse behaviours of small groups can be rectified. The tips then come into their own with useful suggestions.

Results-based training is concerned with getting trainees to learn by themselves and Race comes up with an impressive list of the types of trainees who may be particularly helped including both high and low fliers, those using a second language and even those people who do not like being taught! He provides a very useful and extensive checklist for flexible learning materials. which include details of content, the learning outcomes, structure and layout, and self-assessment questions and activities. Choosing and using computer-based resources is full of sensible common-sense ideas, which agonize over the frequently encountered problems of choice - whether to use proprietary products, adapt, or create programmes from scratch.

The later chapters on helping trainees to work together with computers and make use of email and email groups is still based on sensible common-sense ideas. Advice is there on how to deal with the technophobe and well as the technophile. The practicalities of setting up computers at an unknown location are outlined followed by a computer glossary.

The book ends with a separate chapter on evaluating your training. This is probably the most useful chapter in the book. It provides sound questions to ask on what it is you hope to achieve using a questionnaire, how to structure questions and advice on what to include and what to leave out!

Overall, a brilliant book written in a lively and common-sense style which is bound to inspire a trainer or staff developer to greater things. The book is well laid out but clearly cannot do everything. You still need something that outlines small group activities more clearly and a lot more on the technical side of computers but there are five pages on how you could retrieve this information from the Internet and even what to do it if there is a power cut.

\section{John Sweet \\ UWCM}

Otto Peter, Learning and Teaching in Distance Education: Pedagogical Analyses and Interpretations from an International Perspective. London: Kogan Page, 2001. ISBN: 074943594 10. Paperback, viii + 279 pages, $£ 19.99$.

Government policies promoting widening access as well as an increasing focus on continued professional development and life-long learning have prompted universities to re-evaluate their educational provision. Increasingly, providers (both traditional and commercial) turn to online learning as a means of providing greater flexibility in course delivery. In light of the recent growth of distance education programmes, Learning and Teaching in Distance Education offers a timely and much-needed exploration of distance education's special pedagogy, approaches and their implications for teaching and learning.

The book, an updated version of a previous hardcover edition titled Learning and Teaching in Distance Education: Analyses and Perspectives from an International Perspective, represents excellent value. Case studies have been updated and conveniently consolidated in one chapter. The revised edition also contains new material on virtual universities and under "Further reading' a substantial compilation of the latest 
literature in distance education research (see review by Pearson, $A L T-J 7$, (3), 106-8). Like the first edition, the volume is structured into eight chapters, which are best approached sequentially, as later parts build on the theoretical concepts introduced in the beginning.

A review of the state-of-play in distance education sets the scene in the initial chapter. Firstgeneration distance education methods, such as correspondence courses using print and supplementary media (television, tapes and video), exist in parallel to second- and third- generation methodology. The latter two methods employ teleconferencing and Internet communication technologies, respectively, to overcome the geographical separation of teachers and learners and increase dialogical learning. The advantages and drawbacks of each of these approaches, however, only highlight the dilemma of distance education, which has to balance a high degree of accessibility for many with the quality of interaction in teaching and learning. Further, Peters introduces a framework of five principal factors as the means to differentiate conceptually between distance learning and conventional university education. These factors, namely, technical media, structural handicap, student type, forms of structuralization, and the special combination of forms of teaching and learning serve as criteria for the organization of the text and the analysis and interpretation of distance education pedagogy.

In fact, the substantial contribution and strength of Peters's book lies in its rigorous academic exploration of distance education. There are aspirations to develop a distance-learning science and theory. To this effect, Chapter 2 examines different distance-teaching models employed by different countries and schools of thought. Each of these models seeks to address the structural handicap of distance education, that is, the spatial and communicative or mental distance between teachers and students. Interestingly, experts do not identify a clear preference for one model over others. Rather, weighting three aspects, (1) the level of dialogue, (2) the level of predetermination and structure of the study course and programme, and (3) the level of learner autonomy (self-determination of learning goals), the optimal learning experience depends on the student type and his/her goals and expectations.

The concepts of dialogue, structure and autonomy are further explored, first theoretically and then in their day-to-day application of distance education (Chapters 3 and 4). Here, Peters produces an exhaustive and meticulous list of the different dialogue-enhancing measures and structural approaches applied in the field. The plurality in approaches used is great and if anything, the trend is to intensify the dialogue between teachers and students and amongst students, as communication is seen as an important element of learning and knowledge verification.

Chapters 5 and 6 offer especially stimulating discussion. Approaches in distance education are not only influenced by didactic and technological considerations, but also by economic, social, cultural and political thought. This is reflected in the fact that distance and open learning are increasingly used interchangeably. Education and learning are not completed by the award of a degree but are supposed to continue throughout life; they are supposed to be accessible and open to broad segments of society. Drawing on the relationships between current societal trends, philosophical thought and distance education, Peters evaluates the impact of digital information and communication and speculates on future developments. He outlines how digital communication and virtual learning environments could help provide the conditions to deliver the flexibility and customization that is stipulated by postFordist/post-industrial production if imbedded thoughtfully in suitable infrastructure.

Commendably, Peters does not shy away from controversial issues. He suggests, or rather urges, that educationalists must consider the implications of the fundamental postmodern critique on the values and aims of education. The rising desire of students for self-development, fun and short-term satisfaction are perhaps not deliverable by time-tested models of distance education with centrally planned curricula and students working mostly in isolation; this probably requires new models and further development of the concept of the virtual university.

In Chapter 7, eight detailed institutional case studies illustrate different distance education models and structures. The compilation of a comprehensiye and balanced set of examples, ranging from correspondence studies in South Africa to telecommunication-centred set-ups in North America demonstrates the authors' expertise and broad knowledge of the subject. Chapter 8 recaptures the main themes and provides a final analysis. 
Overall, the book is well written, except perhaps, for the oversight to provide translations for a range of German references, such as 'Einsamkeit und Freiheit' and the 'Wissenschaftsrat'. Frankly, this is an unfortunate omission, as the meaning of these terms contributes significantly to the understanding of the passages and arguments in which they are embedded.

Nonetheless, this second edition of Learning and Teaching in Distance Education is a worthwhile if not essential addition to the library of any academic involved in distance education. Even for those not interested in distance education, the book is a valuable read. The pedagogic concepts and discussions shed new light on traditional university teaching and provide provocative thought for the engagement of universities in online teaching and virtual teaching environments.

Andrea I. Frank

Cardiff University 